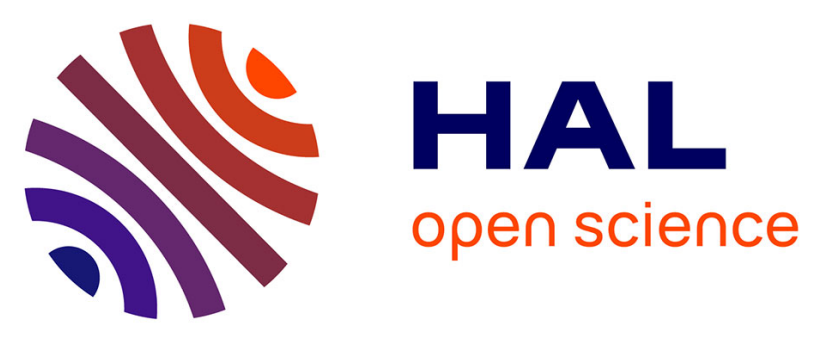

\title{
Ultrasonographic criteria for the diagnosis of erosive rheumatoid arthritis using osteoarthritic patients as controls compared to validated radiographic criteria
}

Camille Roux, Frédérique Gandjbakhch, Audrey Pierreisnard, Marion

Couderc, Cédric Lukas, Racha Masri, Jean-Philippe Sommier, Isabelle

Clerc-Urmès, Cédric Baumann, Isabelle Chary-Valckenaere, et al.

\section{To cite this version:}

Camille Roux, Frédérique Gandjbakhch, Audrey Pierreisnard, Marion Couderc, Cédric Lukas, et al.. Ultrasonographic criteria for the diagnosis of erosive rheumatoid arthritis using osteoarthritic patients as controls compared to validated radiographic criteria. Joint Bone Spine, 2019, 86 (4), pp.467-474. 10.1016/j.jbspin.2019.01.011 . hal-02090349

\section{HAL Id: hal-02090349 \\ https://hal.science/hal-02090349}

Submitted on 25 Oct 2021

HAL is a multi-disciplinary open access archive for the deposit and dissemination of scientific research documents, whether they are published or not. The documents may come from teaching and research institutions in France or abroad, or from public or private research centers.
L'archive ouverte pluridisciplinaire HAL, est destinée au dépôt et à la diffusion de documents scientifiques de niveau recherche, publiés ou non, émanant des établissements d'enseignement et de recherche français ou étrangers, des laboratoires publics ou privés.

\section{(ㄷ)(1) $\$$}

Distributed under a Creative Commons Attribution - NonCommerciall 4.0 International 


\section{Ultrasonographic criteria for the diagnosis of erosive rheumatoid arthritis using osteoarthritic patients as controls compared to validated radiographic criteria}

Camille Roux (1), Frédérique Gandjbakhch (2), Audrey Pierreisnard (2), Marion Couderc ${ }^{(3)}$, Cédric Lukas ${ }^{(4)}$, Racha Masri ${ }^{(1)}$, Jean-Philippe Sommier ${ }^{(1)}$, Isabelle Clerc-Urmes ${ }^{(5)}$, Cédric Baumann ${ }^{(5)}$, Isabelle Chary-Valckenaere ${ }^{(1,6)}$, Damien Loeuille $^{(1,6)}$

${ }^{(1)}$ Department of Rheumatology, University Hospital of Nancy, 54500 Vandoeuvrelès-Nancy, France

${ }^{(2)}$ Department of Rheumatology, Academic Hospital Pitié Salpêtrière, Paris, France

${ }^{(3)}$ Department of Rheumatology, University Hospital of Clermont- Ferrand, 63000 Clermont- Ferrand, France

${ }^{(4)}$ Department of Rheumatology, University Hospital of Lapeyronie, 34000 Montpellier, France

${ }^{(5)}$ Platform of Clinical Research Support PARC (MDS unity), University Hospital of Nancy, 54500 Vandoeuvre-lès-Nancy, France

${ }^{(6)}$ INSERM, CIC-EC CIE6, Nancy, France University Hospital of Nancy, Epidemiology and Clinical Evaluation, 54500 Vandoeuvre-lès-Nancy, France.

\section{CORRESPONDING AUTHOR}

Camille ROUX: Department of Rheumatology University Hospital of Nancy,

54500 Vandoeuvre-lès-Nancy, France

E-mail address: roux.cam@hotmail.fr

Phone number: +33 3831532 03; Fax number: 0383153190 


\section{ABSTRACT}

Objectives: The aims of this study were to compare characteristics of radiography (RX) and ultrasound (US) erosive lesions in rheumatoid arthritis (RA) and osteoarthritis (OA) patients (prevalence, topography and severity), to determine thresholds for the diagnosis of erosive RA based on US and to evaluate the performance of US and RX to establish a diagnosis of erosive RA differentiated from hand $O A$.

Methods: Patients fulfilling ACR 1987 and/or ACR/EULAR 2010 criteria for RA or ACR hand OA criteria were prospectively included. A modified Sharp erosion score was assessed by two blinded readers and one adjudicator for discordant cases (number of eroded joints $\leq$ three). Erosions in US were scored on six bilateral joints (MCP2-3, 5; MTP2-3, 5) with a four-grade scale to calculate total US score for erosions (USSe).

Results: A total of 168 patients were included: $122 \mathrm{RA}$ (32 early RA $<2$ years; 90 late $\mathrm{RA} \geq 2$ years); 46 OA patients. On RX: 42 RA patients ( 6 early; 36 late) and $5 \mathrm{OA}$ patients were eroded according to EULAR 2013 definition criteria with sensitivity at $34.4 \%$ and specificity at $89.1 \%$. On US, 95 RA patients (21 early; 74 late) and $12 \mathrm{OA}$ patients were eroded. Considering at least two joint facets eroded or at least one joint facet eroded at grade 2 on US, sensitivities were good (68-72.1\%) and specificities excellent (89.1-100\%). Agreement between RX and US was excellent (90-92\%). The positive and negative likehood ratios were respectively 3.16 and 0.73 for radiography and 6.64 and 0.31 for US (for two facets eroded).

Conclusion: USSe can differentiate RA from OA in erosive disease and detect two times more patients with erosive $\mathrm{RA}$ than $\mathrm{RX}$ with excellent specificity and agreement.

Key words: rheumatoid arthritis, osteoarthritis, erosion, ultrasonography, radiography, diagnosis. 


\section{Introduction}

Rheumatoid arthritis (RA) is the most prevalent chronic inflammatory joint disease (1) responsible for structural damage. To limit these consequences, an international consensus recommended a therapeutic strategy based on early diagnosis and search for poor prognostic factors in order to optimize the tight control of disease activity.(2) Erosions on radiography (RX), high levels of biologic inflammation parameters, and the presence of anti-cyclic citrullinated protein antibodies (ACPA) (3) are the main predictive factors of bone erosions on radiography, which is the gold standard for visualizing and quantifying bone lesions in RA (erosion and joint space).(4) The modified Sharp/van der Heijde score (5) demonstrated good intraand inter-reader reliabilities, good sensitivity to change (6) and is considered as the standard scoring method for assessing structural damage in RA.

Musculoskeletal ultrasound (US) is booming in clinical practice for the diagnosis and evaluation of inflammatory lesions from inflammatory disorders, and it has been proven to be effective in the evaluation of bone erosions in musculoskeletal disease osteoarthritis (OA) (7), gout (8), and in psoriatic arthritis (PsA) (9). In RA, many studies have shown that US can detect more erosions than RX at the joint level, especially at an early stage of the disease, with higher sensitivity and specificity than $\mathrm{RX}$ when a CT scan is taken as the gold standard imaging method (10).

It is now recognized that PsA (11), connective tissue diseases (12), and metabolic diseases (13), are associated with bone erosions in hands and feet on RX, but these diagnosis, not only based on radiography, are finally established by specific clinical and biological features (14).

In patients over 50 years of age, the diagnosis of RA is usually established based on clinical and biological features. However, the diagnosis of erosive RA disease based on $\mathrm{RX}$ or US is sometimes difficult since bone erosions related to degenerative changes (osteoarthritis) may coexist with erosions due to RA $(15,16)$.

The aims of this study are:

- to compare characteristics of $R X$ and US erosive lesions in RA and OA patients (prevalence, topography and severity),

- to determine thresholds for the diagnosis of erosive RA based on US,

- to compare the performance of US and RX to establish a diagnosis of erosive RA differentiated from hand $O A$. 


\section{Methods}

\subsection{Patients}

All consecutive patients hospitalized in the department of Rheumatology in Hospital of Nancy since 2005 for suspicion of RA were screened. Only patients fulfilling the following inclusion criteria were selected for this study: patients fulfilling ACR 1987 and/or ACR/EULAR 2010 criteria for RA, patients fulfilling only ACR OA criteria of hand OA served as control group (17). US exam and RX exam of hand and feet should be performed within 6 months. The only exclusion criterion was the presence of severe joint deformities that could prevent a complete appropriate US, RX and clinical evaluation. Finally, 122 RA patients and 46 OA patients were included. A complete assessment of their disease was performed (clinical, biological, radiological, and ultrasound evaluations). For RA patients, data collection included the Disease Activity Score 28-joint count (DAS 28) and treatments at the time of evaluation (bDMARD, sDMARD, corticosteroids, and NSAIDs). For OA patients, no treatment has been registered.

\subsection{Biological assessment}

The following measures were assessed: C-reactive protein level (CRP: normal value $<5 \mathrm{mg} / \mathrm{L}$ ), erythrocyte sedimentation rate at the first hour (ESR: normal value $<5$ $\mathrm{mm}$ ), rheumatoid factor (RF) titres (normal value <20 UI), and ACPA titres (normal value $<20 \mathrm{UI})$.

\subsection{Radiography assessment}

Postero-anterior views of hands and antero-posterior views of feet have been obtained according to the usual clinical practice recommendations for patients followed up for RA and for patients suffering from hands and/or feet OA. RX analyses have been performed blindly from clinical and US information's. Two independent 
readers (AP, MC) performed the modified Sharp/van der Heijde score (SHS) for erosions (SHSe) $(18,19)$. with sub-scores for hands and feet. Based on this RX evaluation, patients were classified as erosive RA according to EULAR 2013 Definition (18); an erosive disease is defined when an erosion (defined as a cortical break) is observed in at least three separate joints at any of the following sites: proximal interphalangeal joints (PIP), metacarpophalangeal joints (MCP), wrist (counted as one joint), and metatarsophalangeal joints (MTP) on radiographs of both hands and feet. In the case of discordance between the two readers for a number of eroded joints less than or equal to three (corresponding to the EULAR 2013 Definition of erosive RA), a third reader (ICV) served as adjudicator. For each patient, the SHSe corresponded to the mean score of the two or three readers.

\subsection{Ultrasound assessment}

Standardized US examinations were performed by senior US analysts (ICV, DL, JPS) after several sessions of harmonization for calibration of erosion. The equipment used throughout the study was the same: a Philips HD11 machine with a multi-frequency linear array transducer $(5-12 \mathrm{MHz})$ with the focal length adjusted to the joint depth. US information's were acquired at optimal technical conditions at 12 $\mathrm{MHz}$ (spatial resolution $0.1 \mathrm{~mm}$ ) blinded to clinical, biologic, and radiologic findings. Twelve pre-selected targeted joints have been systematically examined on B mode: MCPs 2, 3, and 5 and MTPs 2, 3, and 5. MCP4 and MTP4 joints are less commonly affected by erosions in RA and were not included $(10,19,20)$; MCP1, PIP and MTP1 joints, which are frequently damaged by degenerative changes or metabolic diseases, have also been excluded (21). Wrists were also excluded because of the lack of precise anatomic localization of erosions when both axial and longitudinal plans were required. Moreover numerous cortical defects and joint ligament attachments were present embarrassing the US exam.

\subsubsection{Localization and grading of erosions}


Erosions were searched on the dorsal (D) and palmar or plantar $(P)$ facets of each joint and on the lateral (L) facet when accessible (MCP2, MCP5 and MTP5). On each facet, erosion was defined as a cortical defect with an irregular bone surface, observed in two perpendicular planes (axial and longitudinal). Erosions were scored semi-quantitatively according to 4 grades: grade $0=$ no erosion; grade $1=$ single erosion $<2 \mathrm{~mm}$ in its largest dimension; grade $2=$ single erosion $\geq 2 \mathrm{~mm}$ and $<3 \mathrm{~mm}$ in its largest dimension or no more than two erosions $<2 \mathrm{~mm}$; and grade $3=$ single erosion $\geq$ to $3 \mathrm{~mm}$ in its largest dimension or multiple erosions $(>n=2)$. The total US score for erosions (USSe) was the sum of erosion grades for all eroded joints facets $(\mathrm{n}=30)$ and ranged from 0 to 90 .

\subsubsection{Intra- and inter-examiner US reproducibility}

Intra-examiner reproducibility was assessed on 11 RA patients according to two complete examinations per patient within 24 hours. Inter-examiner reproducibility was assessed on 11 RA patients examined independently on the same day by each US operator. For intra-examiner reproducibility, the median value of the total US erosion score was 21 (range: 3-35) for the first exercise and 21 (range: 3-34) for the second. The intra-class correlation coefficient (ICC) values of the erosion US score for intraand inter-examiner studies were 0.96 (Cl95: 0.93-0.98) and 0.97 (Cl95: 0.92-0.99), respectively. The inter reader reliability for the diagnosis of erosion was excellent (Gwet's AC1: 0.80)

\subsection{Statistical analysis}

Characteristics of patients were described by number and percentage for categorical variables and mean and standard deviation for continuous variables. For comparison, parametric statistics (Chi-square test and ANOVA F-statistic) or non-parametric statistics (Fisher exact, Wilcoxon tests) were used when appropriate. Inter-reader reliability for radiography and ultrasonography were tested using Gwet's AC1 statistic for binary variables and intra-class correlation coefficient (ICC) for continuous variable. The diagnostic performances (sensitivity, specificity, positive predictive value (PPV), and negative predictive value (NPV)) have been analysed. Sensitivity 
analyses of the threshold for dichotomizing the diagnosis of erosive RA based on RX and US were performed. Alpha risk was set at $5 \%$ for all analyses. These statistical analyses were performed using SAS 9.4 software (SAS Institute, Inc, Cary, N.C.). The ethical committee of Nancy approved this study in June 2017 (Number of recording: R2017-16).

\section{Results}

\subsection{Demographic characteristics of the population}

During the study period, 168 patients were included. Among them, 122 patients $(72.6 \%)$ belonged to the RA group and were separated into early RA (disease duration of less than 2 years, $n=32$ ) and late $R A$ (disease duration of 2 years or more, $n=90)$, and 46 patients $(27,4 \%)$ belonged to the OA group. Gender and age did not differ between all groups. The demographic characteristics are detailed in table1.

\subsection{Radiographic evaluation}

\subsubsection{Reproducibility}

The ICC between the two readers was 0.81 (IC95: 0.75, 0.86). Among the 168 exams, $99(58.9 \%)$ matched between the two readers for a number of eroded joints less than or equal to three (data not shown). A third reading was necessary for 69 patients (41.1\%) who were younger ( $58.8 \pm 13.6$ vs $53.1 \pm 11.2$; $p=0.0035$ ).

\subsubsection{Localization and severity of erosions}

For the 168 patients, 2,856 joints were analysed (2,074 joints in the RA group and 782 in the $O A$ group): 72 patients ( 12 early $R A$ and 60 late $R A$ ) and 12 patients were eroded in RA and OA groups respectively. There were 301 (10.5\%) eroded joints, $272(9.5 \%)$ in the RA group and $29(1.0 \%)$ in the OA group $(p<.0001)$ (table 2$)$. Erosions were preferentially observed in wrists and PIPs in the OA group, and in 
MTP5 joints and wrists in the RA group (table 2). The mean SHSe was $1.09 \pm 2.58$ and $5.98 \pm 11.09$ in the OA and RA groups, respectively $(p<.0001)(1.62 \pm 3.09$ in early RA, $7.53 \pm 12.44$ in late RA groups, $(p<.0001)$ ) (table 2).

\subsubsection{Number of patients (RA and OA) fulfilling to the definition of erosive RA regarding to EULAR 2013 definition}

In the OA group, 12 patients (26.1\%) presented at least one erosion, for whom five (10.8\%) satisfied with EULAR 2013 definition of erosive disease (table 2). In the RA group, 72 patients $(59.0 \%)$ presented at least one erosion for whom 42 (34.4\%) satisfied with EULAR 2013 definition of erosive disease (six (4.9\%) in early RA and $36(29.5 \%)$ in late RA) (table 2). When OA patients served as controls, the EULAR 2013 definition of erosive disease with a threshold of three eroded joints was confirmed as the best compromise in terms of sensitivity and specificity $(34.4 \%$ and $89.1 \%$, respectively) in comparison with other combinations; see results in table 3 . With a threshold set at three eroded joints, the positive and negative likehood ratios were 3.16 and 0.73 respectively. Considering the severity of erosion at the joint level, whatever its localization, an erosion of a grade 2 had a sensitivity of $18.8 \%$ and a specificity of $86.9 \%$; see table 3 . Analyses for each threshold and their PPV and NPV are detailed in table 3.

\subsection{Ultrasound evaluation}

\subsubsection{Localization and severity of erosions}

For the 168 patients, 5,040 joint facets were analysed (3,660 in the RA group and 1,380 in the OA group): 95 patients (77.9\%) (21 (17.2\%) early RA and $74(63.9 \%)$ late RA) and 12 patients (26.1\%) were eroded in RA and OA groups, respectively. There was a total of 549 eroded joint facets (10.9\%), $537(10.6 \%)$ in the RA group and $12(0.2 \%)$ in the OA group $(p<.001)$. In the OA group, $12(26.1 \%)$ patients presented with one erosion, and five patients had an erosion of grade 2 (table 4). In

RA groups, the distribution of erosions prevailed on lateral facets, independent of disease duration. MTP5 joints were the most frequently eroded joints $(46.5 \%)$, 
followed by MCP2 joints (27.3\%) and MCP5 joints (14.7\%); details are presented in table 4. The severity of erosions prevailed on MTP5 followed by MCP2 joints (table 4). The mean $( \pm S D)$ USSe was $0.4( \pm 0.7)$ in the OA group and $10.0( \pm 12.0)$ in the RA group $(p<.0001)$. The difference between mean USSe between early and late RA patients reached statistical significance (4.3 \pm 7.5 in the early RA group and 12.1 \pm 12.7 in the late RA group $(p<.0001))$ and the difference was also statistically significant between OA and early RA patients $(p<.0001)$ (table 4$)$.

\subsubsection{Definition of erosive RA on ultrasound}

For the diagnosis of erosive RA, the presence of at least two eroded joint facets presented the better compromise in terms of sensitivity $(68.0 \%)$ and specificity (100.0\%) in comparison with other combinations (table 3) The positive likehood ratio were not computable (specificity $=100 \%$ ) and the negative likelihood ratio was 0.31 . Considering the severity of the erosion at the joint facet level, whatever its localization, the presence of one erosion of grade 2 presented the best sensitivity and specificity ratios $(72.1 \%$ and $89.1 \%$, respectively) compared to other combinations. The positive and negative likelihood ratios were 6.64 and 0.31 respectively. The analysis for each threshold is detailed in table 3 . According to ultrasound assessment, $83 \mathrm{RA}$ (14 early RA and 69 late RA) and zero OA patient satisfied with definition of erosive RA based on US with at least two eroded joint facets. Considering at least a grade 2 for erosion severity on at least one joint facet as the diagnosis threshold, 81 RA patients (11 early RA and 70 late RA) and five OA patients were classified with erosive disease.

\subsection{Comparison of performance of radiography and ultrasound}

The agreement between RX (threshold of 3 eroded joints) and US (threshold of two joint facets eroded) for erosive RA was 90.4\%: 38 US patients with erosive RA were identified among the 42 erosive RA patients on radiography (three out of six in early $R A$ and 35 out of 36 in late RA). In the four discordant cases (positive RX and negative US), three patients presented one US erosion (two patients with grade 2 and one with grade 1), and the other patient presented no erosion. Interestingly, the 
eroded sites based on radiography for three of the patients were wrists and MCP1, sites that were not explored using US. For the 45 patients with negative $R X$ and positive US, the mean $( \pm S D)$ number of eroded joint facets was $4.38( \pm 2.52)$ with a mean USSe of 8.91 ( \pm 6.78 ), mainly localized on MTP5 followed by MCP2 then MCP5 joints.

The agreement between RX (threshold of 3 eroded joints) and US (threshold of at least a grade 2 at the joint facet level) for erosive RA was 92.8\%: 39 US patients with erosive RA were identified among the 42 erosive RA patients based on radiography (four out of six in early RA and 35 out of 36 in late RA). In the three discordant cases (positive RX and negative US), one patient presented one erosion of grade 1 , the second patient presented two erosions of grade 1 and the last patient had no erosion according to the ultrasound evaluations. According to the radiography evaluations, the three patients presented erosions on wrists $(n=3), \operatorname{MCP} 1(n=2)$, and MCP4 joint $(n=1)$. For the 42 patients with negative $R X$ and positive US, the mean ( $\pm S D)$ number of eroded joint facets was $4.3( \pm 2.7)$ with a mean USSe of $9.3( \pm 6.8)$.

\section{Discussion}

The aim of this study was to compare radiography and ultrasound erosion characteristics (prevalence, localization and severity) in RA and OA patients in order to establish thresholds for the diagnosis of erosive RA on US, according to two different approaches: 1) a minimal number of eroded joint facets 2) a minimal grade of severity for at least one joint facet eroded. We demonstrated through the use of these two approaches that ultrasound has a better sensitivity and similar specificity in comparison to radiography to detect patients with erosive disease.

This technique also offers many advantages (accessibility, cost, lack of irradiation) with good intra- and inter-reliabilities for assessing structural damage and especially erosion. Like other authors, we demonstrated excellent intra-reader reliability (2227 ), at the joint facet level with same ranged of values calculated by Wakefield and Zayat.

In this study, US joint examination was limited at some selected joints because not all the joints evaluated using the modified SHS can be explored in clinical practice. We decided, as other authors have done, to exclude the wrist because of its anatomic 
characteristics that make it difficult to localize erosions with precision in axial and longitudinal planes, except for the ulnar styloid process, where detection of these erosions seem easier (22). We also excluded: MCP1, MTP1 and all PIP joints because these joints may be eroded by other musculoskeletal diseases osteoarthritis (the most prevalent disease in patients over 50 years old) (21) and patients with severe joint deformities because this exam performs poorly in this situation and is inappropriate (joints not well visualized and erosion not clearly identified on two perpendicular planes) (28).

Our results confirmed that the MTP5 joint and the MCP2 joint are the most prevalent eroded joints especially in the lateral facets in RA, as shown by other studies.(22,28,29) In OA, MCP2 followed by MTP5 joints are the most frequently eroded joints with a prevalence varying from 5 to $13 \%$ according to the joint examined, but neither of these joints are severely eroded (22). In our study, five OA patients presented with erosion of grade 2 (10.3\%), whereas Zayat, et al. (22) did not find severe erosion in OA patients. With a threshold of two eroded joint facets, whatever the grade of severity observed, we calculated a sensitivity of $68.0 \%$ with a specificity of $100.0 \%$. Our results showed that RA, in comparison to hand OA, affects more joints with more severe bone damages in early and late stages of RA disease. A recent meta-analysis and other studies also showed that erosions in RA are larger and bigger than in other rheumatisms, with a "target size" varying between 2 and 2.5 $\mathrm{mm}(24,28,30)$. Our study confirmed that erosion with the same size (grade 2: single erosion $\geq 2 \mathrm{~mm}$ and $<3 \mathrm{~mm}$ in its largest dimension or no more than two erosions $<2$ $\mathrm{mm}$ ) presented the best compromise in terms of sensitivity and specificity in comparison to OA patients. It is true that an erosion on ultrasound is defined by a cortical defect observed on two planes (axial and longitudinal) and is not always related to musculoskeletal damage but may be related to physiological "vascular channels" that are mainly observed on the plantar facet $(30,31)$. These vascular channels are probably graded in the same manner (frequency and severity) in our population, independent of the disease. Osteophytes may also mimic erosion but are rarely observed in the two planes of the examination. In our study, no significant difference with respect to age or gender was noted between the two groups (OA versus $R A$ patients), limiting the biases related to age structural damages during the ultrasonography examination. 
In the literature, four scores of US erosions were compared to radiographic assessment $(26,32,33,34)$. The authors showed the superiority of ultrasound to detect erosions, but they were unable to define a threshold from which an erosive RA disease on US can be established due to the lack of a control group.

On radiography, the diagnosis of erosive RA in hands and feet is routinely performed in clinical practice. The diagnosis of eroded disease in RA is crucial since structural damages are associated to poor functional outcome and are considered as poor prognostic factors leading to a more aggressive therapy. RX serves as the gold standard for erosive disease if at least three selected joints are eroded (18). Radiography presents many advantages: the views and the technical parameters are well defined and the diagnosis of erosive RA is easily established after a careful reading performed for few seconds. The modified SHS is considered one of the standard methods for assessing structural effects of RA DMARDs (synthetic or biologic) in clinical trials because it presents excellent intra- or inter-reader reliabilities and a good sensitivity to change (6). To limit reading biases, two senior readers of the ESPOIR's cohort blindly assessed the SHS, and an adjudication was made by the third senior reader, On the 44 joints assessed, MTP5 and wrists joints were most frequently eroded as described in the literature (35). When OA patients served as a control group, the diagnosis of erosive RA disease based on radiography was calculated with a sensitivity of $34.4 \%$ and a specificity of $89.1 \%$. As a result, the positive and negative like ratios were 3.16 and 0.73 respectively. These results are close to those validated by the EULAR task force in two cohorts of early arthritis (a sensitivity of $15-29 \%$ and a specificity of $>80 \%)(26,36)$.

In 2000, Wakefield, et al. (10) demonstrated that ultrasonography permits to detect, at the joint level, more erosions in early and late RA than radiography. The superiority of ultrasound was confirmed in other studies $(20,37)$ but also when CT scans served as the gold standard to evaluate both imaging techniques (38). Our study demonstrated that ultrasound detected 2.0 times more eroded RA patients than radiography with a threshold of at least two eroded joint facets and 1.9 times more patients with a threshold of at least one erosion of grade 2 at a joint facet level with excellent specificities (100.0\% and $89.1 \%$, respectively) when compared to OA patients. Moreover, we showed that ultrasonograhic assessment was able to detect two times more patients with early RA erosive disease than radiograph (14 or 11 on US versus 6 on RX). Erosion diagnosis on US is relevant since a longitudinal follow- 
up in the ESPOIR Cohort demonstrated that US erosion at baseline was predictive of eroded joint on radiography (OR=1.44 (IC95\%: 1.01-1.98)) at one year (39).

This pilot study performed by trained sonographers required the development of the USSe score according to an external validation process such as the OMERACT filter. The sensitivity to change should also be tested, and the relationship between bone erosion and joint inflammation at the joint level should also be investigated. To reduce the time of the US examination, varying between 10 and 20 minutes, the number of joint facets could probably be optimized. Of course, radiographic and ultrasonographic patterns of erosions in other musculoskeletal diseases were not evaluated in this study and could be detemined in the future. Finally, joint space assessment, not performed in this study and recently validated by Mandl et al. (40), should also be investigated according to a complementary manner.

Finally, we demonstrated that bone erosion assessed using US was reliable and may be observed in both OA and RA diseases, with a higher prevalence and severity in RA. According to two different criteria (number of facets eroded and severity of erosion at the joint facet level) the USSe detected approximately 2.0 times more eroded RA patients than radiography, especially in early RA.

\section{Disclosure of interest}

The authors declare that they have no competing interest. 


\section{References}

1. Alamanos $\mathrm{Y}$, Voulgari PV, Drosos AA. Incidence and prevalence of rheumatoid arthritis, based on the 1987 American College of Rheumatology criteria: a systematic review. Semin Arthritis Rheum. $2006 ; 36: 182-8$.

2. van Aken J, Lard LR, le Cessie S, Hazes JMW, Breedveld FC, Huizinga TWJ. Radiological outcome after four years of early versus delayed treatment strategy in patients with recent onset rheumatoid arthritis. Ann Rheum Dis. 2004 ;63:274-9. 3. Aletaha D, Neogi T, Silman AJ, Funovits J, Felson DT, Bingham CO, et al. 2010 rheumatoid arthritis classification criteria: an American College of Rheumatology/European League Against Rheumatism collaborative initiative. Ann Rheum Dis. $2010 ; 69: 1580-8$.

4. Baillet A, Gaujoux-Viala C, Mouterde G, Pham T, Tebib J, Saraux A, et al. Comparison of the efficacy of sonography, magnetic resonance imaging and conventional radiography for the detection of bone erosions in rheumatoid arthritis patients: a systematic review and meta-analysis. Rheumatol Oxf Engl. 2011 ;50:1137-47.

5. van der Heijde DM, van Leeuwen MA, van Riel PL, van de Putte LB. Radiographic progression on radiographs of hands and feet during the first 3 years of rheumatoid arthritis measured according to Sharp's method (van der Heijde modification). J Rheumatol. 1995;22:1792-6.

6. van der Heijde D, Dankert T, Nieman F, Rau R, Boers M. Reliability and sensitivity to change of a simplification of the Sharp/van der Heijde radiological assessment in rheumatoid arthritis. Rheumatol Oxf Engl. 1999;38:941-7.

7. Usón J, Fernández-Espartero C, Villaverde V, Condés E, Godo J, MartínezBlasco MJ, et al. Symptomatic and asymptomatic interphalageal osteoarthritis: An ultrasonographic study. Reumatol Clin. 2014;10:278-82.

8. Gutierrez M, Schmidt WA, Thiele RG, Keen HI, Kaeley GS, Naredo E, et al. International Consensus for ultrasound lesions in gout: results of Delphi process and web-reliability exercise. Rheumatol Oxf Engl. 2015;54:1797-805.

9. Weiner SM, Jurenz S, Uhl M, Lange-Nolde A, Warnatz K, Peter HH, et al. Ultrasonography in the assessment of peripheral joint involvement in psoriatic arthritis $\square$ : a comparison with radiography, MRI and scintigraphy. Clin Rheumatol. 2008;27:983-9.

10. Wakefield RJ, Gibbon WW, Conaghan PG, O'Connor P, McGonagle D, Pease $\mathrm{C}$, et al. The value of sonography in the detection of bone erosions in patients with rheumatoid arthritis: A comparison with conventional radiography. Arthritis Rheum. 2000;43:2762-70.

11. Jadon DR, Shaddick G, Tillett W, Korendowych E, Robinson G, Waldron N, et al. Psoriatic Arthritis Mutilans: Characteristics and Natural Radiographic History. J Rheumatol. 2015;42:1169-76.

12. Alarcón-Segovia D, Abud-Mendoza C, Diaz-Jouanen E, Iglesias A, De los Reyes V, Hernández-Ortiz J. Deforming arthropathy of the hands in systemic lupus erythematosus. J Rheumatol. 1988;15:65-9.

13. Dalbeth N, Clark B, Gregory K, Gamble G, Sheehan T, Doyle A, et al. Mechanisms of bone erosion in gout: a quantitative analysis using plain radiography and computed tomography. Ann Rheum Dis. 2009;68:1290-5.

14. Rudwaleit M, van der Heijde D, Landewé R, Listing J, Akkoc N, Brandt J, et al. The development of Assessment of SpondyloArthritis international Society 
classification criteria for axial spondyloarthritis (part II): validation and final selection. Ann Rheum Dis. 2009;68:777-83.

15. Guillemin F, Saraux A, Guggenbuhl P, Roux CH, Fardellone P, Le Bihan E, et al. Prevalence of rheumatoid arthritis in France: 2001. Ann Rheum Dis. 2005;64:1427-30.

16. Haugen IK, Englund M, Aliabadi P, Niu J, Clancy M, Kvien TK, et al.

Prevalence, incidence and progression of hand osteoarthritis in the general population: the Framingham Osteoarthritis Study. Ann Rheum Dis. 2011;70:1581-6. 17. Altman R, Alarcón G, Appelrouth D, Bloch D, Borenstein D, Brandt K, et al. The American College of Rheumatology criteria for the classification and reporting of osteoarthritis of the hand. Arthritis Rheum. 1990;33:1601-10.

18. van der Heijde D, van der Helm-van Mil AHM, Aletaha D, Bingham CO, Burmester GR, Dougados M, et al. EULAR definition of erosive disease in light of the 2010 ACR/EULAR rheumatoid arthritis classification criteria. Ann Rheum Dis. 2013;72:479-81.

19. Scheel AK, Hermann K-GA, Ohrndorf S, Werner C, Schirmer C, Detert J, et al. Prospective 7 year follow up imaging study comparing radiography, ultrasonography, and magnetic resonance imaging in rheumatoid arthritis finger joints. Ann Rheum Dis. 2006;65:595-600.

20. Szkudlarek M, Klarlund M, Narvestad E, Court-Payen M, Strandberg C, Jensen KE, et al. Ultrasonography of the metacarpophalangeal and proximal interphalangeal joints in rheumatoid arthritis: a comparison with magnetic resonance imaging, conventional radiography and clinical examination. Arthritis Res Ther. 2006;8:R52.

21. lagnocco A, Coari G. Usefulness of high resolution US in the evaluation of effusion in osteoarthritic first carpometacarpal joint. Scand J Rheumatol. 2000;29:170-3.

22. Zayat AS, Ellegaard K, Conaghan PG, Terslev L, Hensor EMA, Freeston JE, et al. The specificity of ultrasound-detected bone erosions for rheumatoid arthritis. Ann Rheum Dis. 2015;74:897-903.

23. Wakefield RJ, Gibbon WW, Conaghan PG, O'Connor P, McGonagle D, Pease $\mathrm{C}$, et al. The value of sonography in the detection of bone erosions in patients with rheumatoid arthritis: a comparison with conventional radiography. Arthritis Rheum. 2000;43:2762-70.

24. Bajaj S, Lopez-Ben R, Oster R, Alarcón GS. Ultrasound detects rapid progression of erosive disease in early rheumatoid arthritis: a prospective longitudinal study. Skeletal Radiol. 2007;36:123-8.

25. Scheel A, Schmidt W, Hermann K, Bruyn G, D’Agostino M, Grassi W, et al. Interobserver reliability of rheumatologists performing musculoskeletal ultrasonography: results from a EULAR "Train the trainers" course. Ann Rheum Dis. 2005;64:1043-9.

26. Funck-Brentano T, Etchepare F, Joulin SJ, Gandjbakch F, Pensec VD, Cyteval $\mathrm{C}$, et al. Benefits of ultrasonography in the management of early arthritis: a cross-sectional study of baseline data from the ESPOIR cohort. Rheumatol Oxf Engl. 2009;48:1515-9.

27. Gutierrez M, Filippucci E, Ruta S, Salaffi F, Blasetti P, Di Geso L, et al. Interobserver reliability of high-resolution ultrasonography in the assessment of bone erosions in patients with rheumatoid arthritis: experience of an intensive dedicated training programme. Rheumatol Oxf Engl. 2011;50:373-80.

28. Szkudlarek M, Terslev L, Wakefield RJ, Backhaus M, Balint PV, Bruyn GAW, 
et al. Summary Findings of a Systematic Literature Review of the Ultrasound

Assessment of Bone Erosions in Rheumatoid Arthritis. J Rheumatol. 2016;43:12-21.

29. Tămaş M-M, Filippucci E, Becciolini A, Gutierrez M, Di Geso L, Bonfiglioli K, et al. Bone erosions in rheumatoid arthritis: ultrasound findings in the early stage of the disease. Rheumatol Oxf Engl. 2014;53:1100-7.

30. Finzel S, Ohrndorf S, Englbrecht M, Stach C, Messerschmidt J, Schett G, et al. A detailed comparative study of high-resolution ultrasound and micro-computed tomography for detection of arthritic bone erosions. Arthritis Rheum. 2011;63:12316.

31. Etchepare F. Ultrasonography and rheumatoid arthritis. Ultrason Rheum Arthritis Engl. 2015;82:208-11.

32. Luz KR, Pinheiro MM, Petterle GS, Dos Santos MF, Fernandes ARC, Natour $\mathrm{J}$, et al. A new musculoskeletal ultrasound scoring system (US10) of the hands and wrist joints for evaluation of early rheumatoid arthritis patients. Rev Bras Reumatol. 2016; 56:421-31.

33. Ohrndorf S, Messerschmidt J, Reiche BE, Burmester GR, Backhaus M. Evaluation of a new erosion score by musculoskeletal ultrasound in patients with rheumatoid arthritis: is US ready for a new erosion score? Clin Rheumatol. 2014;33:1255-62.

34. Leng X, Xiao W, Xu Z, Zhu X, Liu Y, Zhao D, et al. Ultrasound7 versus ultrasound 12 in monitoring the response to infliximab in patients with rheumatoid arthritis. Clin Rheumatol. 2016;35:587-94.

35. Brook A, Corbett M. Radiographic changes in early rheumatoid disease. Ann Rheum Dis. 1977;36:71-3.

36. de Rooy DPC, van der Linden MPM, Knevel R, Huizinga TWJ, van der Helmvan Mil AHM. Predicting arthritis outcomes--what can be learned from the Leiden Early Arthritis Clinic? Rheumatol Oxf Engl. 2011;50:93-100.

37. Szkudlarek M, Narvestad E, Klarlund M, Court-Payen M, Thomsen HS, Østergaard M. Ultrasonography of the metatarsophalangeal joints in rheumatoid arthritis: comparison with magnetic resonance imaging, conventional radiography, and clinical examination. Arthritis Rheum. 2004;50:2103-12.

38. Døhn UM, Ejbjerg BJ, Court-Payen M, Hasselquist M, Narvestad E,

Szkudlarek $\mathrm{M}$, et al. Are bone erosions detected by magnetic resonance imaging and ultrasonography true erosions? A comparison with computed tomography in rheumatoid arthritis metacarpophalangeal joints. Arthritis Res Ther. 2006;8:R110. 39. Funck-Brentano T, Gandjbakhch F, Etchepare F, Jousse-Joulin S, Miquel A, Cyteval $\mathrm{C}$, et al. Prediction of radiographic damage in early arthritis by sonographic erosions and power Doppler signal: a longitudinal observational study. Arthritis Care Res. 2013;65:896-902.

40. Mandl P, Supp G, Baksa G, Radner H, Studenic P, Gyebnar J, et al. Relationship between radiographic joint space narrowing, sonographic cartilage thickness and anatomy in rheumatoid arthritis and control joints. Ann Rheum Dis. 2015;74:2022-7. 
Table 1 Characteristics of patients

\begin{tabular}{|c|c|c|c|c|c|c|c|c|}
\hline & \multicolumn{2}{|c|}{$\begin{array}{l}\text { Rheumatoid Arthritis } \\
\qquad \begin{array}{c}\mathbf{N}=\mathbf{1 2 2} \\
(72.6 \%)\end{array}\end{array}$} & \multicolumn{2}{|c|}{$\begin{array}{c}\begin{array}{c}\text { Rheumatoid Arthritis } \\
<2 \text { years } \\
\mathbf{N}=32 \\
(19.0 \%)\end{array} \\
\end{array}$} & \multicolumn{2}{|c|}{$\begin{array}{c}\text { Rheumatoid Arthritis } \\
\geq 2 \text { years } \\
\mathrm{N}=90 \\
(53.6 \%) \\
\end{array}$} & \multicolumn{2}{|c|}{$\begin{array}{l}\text { Osteoarthritis } \\
\qquad \begin{array}{c}\mathbf{N}=46 \\
(27.4 \%) \\
\end{array}\end{array}$} \\
\hline & $N(\%)$ & Mean(SD) & $\mathrm{N}(\%)$ & Mean(SD) & $\mathrm{N}(\%)$ & Mean(SD) & $\mathrm{N}(\%)$ & Mean(SD) \\
\hline Age & 122 & $54.9(13.5)$ & 32 & $54.3(15.7)$ & 90 & $55.1(12.7)$ & 46 & $56.8(9.6)$ \\
\hline \multicolumn{9}{|l|}{ Gender } \\
\hline Male & $34(27.9)$ & & $10(31.3)$ & & $24(26.7)$ & & $10(21.7)$ & 21.7 \\
\hline Female & $88(72.1)$ & & $22(68.8)$ & & $66(73.3)$ & & $36(78.3)$ & 78.3 \\
\hline Disease duration (years) & 122 & $7.1(7.2)$ & 32 & $0.9(0.4)$ & 90 & $9.3(7.1)$ & 46 & $6.2(8.1)$ \\
\hline Delay between RX and US (days) & 122 & $0.6(6.9)$ & 32 & $0.8(7.5)$ & 90 & $0.5(6.7)$ & 46 & $39.7(269.2)$ \\
\hline NSAIDs & 16(13.1) & & $1(3.1)$ & & $15(16.7)$ & & 0 & 0.0 \\
\hline Corticosteroids & $68(55.7)$ & & $18(56.3)$ & & $50(55.6)$ & & 0 & 0.0 \\
\hline sDMARDS & $94(77)$ & & $23(71.9)$ & & $71(78.9)$ & & 0 & 0.0 \\
\hline bDMARD & $37(30.3)$ & & $2(6.3)$ & & $35(38.9)$ & & 0 & 0.0 \\
\hline ESR & 121 & $22.5(20.2)$ & 32 & $32.2(26.5)$ & 89 & $19.1(16.3)$ & 0 & \\
\hline CRP (mg/l) & 122 & 10.8(22.6) & 32 & $19.5(31.6)$ & 90 & $7.7(17.6)$ & 0 & \\
\hline ACPA & $84(68.9)$ & & $21(65.6)$ & & $63(70.0)$ & & 0 & 0.0 \\
\hline ACPA (titers) & 106 & $357.7(696.1)$ & 27 & $526.1(893.5)$ & 79 & $300.1(610.8)$ & 0 & \\
\hline RF & $70(57.4)$ & & $17(53.1)$ & & $53(58.9)$ & & 0 & 0.0 \\
\hline RF (titers) & 98 & $88.4(161.8)$ & 27 & $69.5(139.2)$ & 71 & $95.5(170.0)$ & 0 & \\
\hline DAS 28 & 117 & $3.6(1.4)$ & 29 & $4.3(1.8)$ & 88 & $3.4(1.2)$ & 0 & \\
\hline
\end{tabular}

N: number; SD: Standard deviation; NSAIDS: non-steroidal anti-inflammatory drugs, sDMARDs: synthetic DMARDS, bDMARDs: biologic DMARDS, ESR: erythrocyte sedimentation rate, CRP: Creactive protein, ACPA: anti-cyclic citrullinated peptide antibodies, RF: rheumatoid factor, DAS 28: Disease Activity Score 28-joint count. 
Table 2 Distribution and severity of erosions on radiography according to modified Sharp/van der Heijde scoring

\begin{tabular}{|c|c|c|c|c|c|c|c|c|c|c|c|c|c|c|c|c|c|c|c|c|c|c|}
\hline & WRIST & MCP1 & MCP2 & MCP3 & MCP4 & MCP5 & IPP1 & IPP2 & IPP3 & IPP4 & IPP5 & $\begin{array}{c}\text { Total } \\
\text { Hands }\end{array}$ & MTP1 & MTP2 & MTP3 & MTP4 & MTP5 & IP1 & $\begin{array}{l}\text { Total } \\
\text { Feet }\end{array}$ & $\begin{array}{c}\text { Total } \\
\text { Hands } \\
\text { +Feet }\end{array}$ & $\begin{array}{c}\text { Mean of } \\
\text { eroded } \\
\text { joints } \pm S D\end{array}$ & $\begin{array}{c}\text { Mean } \\
\text { SHSe } \\
\pm S D\end{array}$ \\
\hline \multicolumn{23}{|c|}{ Rheumatoid arthritis } \\
\hline Erosion $(\mathrm{N})$ & 50 & 17 & 23 & 12 & 4 & 5 & 0 & 2 & 6 & 2 & 1 & 122 & 16 & 20 & 24 & 17 & 63 & 10 & 150 & 272 & & \\
\hline SHSe mean & 0,27 & 0,14 & 0,25 & 0,11 & 0,04 & 0,07 & 0 & 0,01 & 0,08 & 0,01 & 0,02 & & 0,18 & 0,28 & 0,35 & 0,21 & 0,9 & 0,08 & & & 2,23 & 5,98 \\
\hline SD & 0,74 & 0,56 & 0,87 & 0,51 & 0,31 & 0,5 & 0 & 0,14 & 0,54 & 0,15 & 0,26 & & 0,76 & 1,08 & 1,27 & 0,96 & 1,79 & 0,43 & & & 3,1 & 11,09 \\
\hline \multicolumn{23}{|c|}{ Early rheumatoid arthritis } \\
\hline Erosion (N) & 5 & 2 & 1 & 1 & 1 & 1 & 0 & 2 & 1 & 0 & 0 & 14 & 1 & 0 & 3 & 2 & 8 & 3 & 17 & 31 & & \\
\hline SHSe mean & 0,04 & 0,04 & 0,02 & 0,02 & 0,03 & 0,02 & 0 & 0,05 & 0,02 & 0 & 0 & & 0,02 & 0 & 0,07 & 0,1 & 0,33 & 0,05 & & & 0,97 & 1,62 \\
\hline SD & 0,16 & 0,21 & 0,17 & 0,17 & 0,25 & 0,13 & 0 & 0,26 & 0,17 & 0 & 0 & & 0,17 & 0 & 0,35 & 0,6 & 1,04 & 0,25 & & & 1,58 & 3,09 \\
\hline \multicolumn{23}{|c|}{ Late rheumatoid arthritis } \\
\hline Erosion $(\mathrm{N})$ & 45 & 15 & 22 & 11 & 3 & 4 & 0 & 0 & 5 & 2 & 1 & 108 & 15 & 20 & 21 & 15 & 55 & 7 & 133 & 241 & & \\
\hline SHSe mean & 0,35 & 0,18 & 0,33 & 0,14 & 0,04 & 0,08 & 0 & 0 & 0,1 & 0,02 & 0,02 & & 0,23 & 0,38 & 0,45 & 0,25 & 1,1 & 0,09 & & & 2,68 & 7,53 \\
\hline SD & 0,85 & 0,64 & 0,99 & 0,58 & 0,33 & 0,58 & 0 & 0 & 0,62 & 0,18 & 0,3 & & 0,88 & 1,25 & 1,45 & 1,06 & 1,96 & 0,48 & & & 3,38 & 12,44 \\
\hline \multicolumn{23}{|c|}{ Osteoarthritis } \\
\hline Erosion (N) & 10 & 0 & 1 & 0 & 0 & 0 & 0 & 4 & 5 & 5 & 0 & 25 & 2 & 1 & 0 & 0 & 0 & 1 & 4 & 29 & & \\
\hline SHSe mean & 0,06 & 0 & 0,03 & 0 & 0 & 0 & 0 & 0,09 & 0,14 & 0,17 & 0 & & 0,03 & 0,01 & 0 & 0 & 0 & 0,01 & & & 0,63 & 1,09 \\
\hline SD & 0,21 & 0 & 0,31 & 0 & 0 & 0 & 0 & 0,44 & 0,6 & 0,7 & 0 & & 0,19 & 0,14 & 0 & 0 & 0 & 0,1 & & & 1,24 & 2,58 \\
\hline
\end{tabular}


Table 3 Diagnostic values for erosive RA of radiography and ultrasonography considering the number of eroded joints or the grade of erosion at the joint level.

\begin{tabular}{|c|c|c|c|c|c|}
\hline & \multicolumn{2}{|c|}{ Sensitivity } & Specificity & PPV & NPV \\
\hline \multicolumn{6}{|c|}{ Number of eroded joints or joint facets } \\
\hline \multirow[t]{3}{*}{$\mathbf{R X}$} & 2 & 43.4 & 80.4 & 85.4 & 34.9 \\
\hline & $3^{*}$ & 34.4 & 89.1 & 89.4 & 33.9 \\
\hline & 4 & 26.2 & 95.6 & 94.1 & 32.8 \\
\hline \multirow[t]{5}{*}{ US } & 1 & 77.9 & 73.9 & 88.8 & 55.7 \\
\hline & 2 & 68.0 & 100.0 & 100.0 & 54.1 \\
\hline & 3 & 58.2 & 100.0 & 100.0 & 47.4 \\
\hline & 4 & 45.9 & 100.0 & 100.0 & 41.1 \\
\hline & 5 & 36.9 & 100.0 & 100.0 & 37.4 \\
\hline \multicolumn{6}{|c|}{ Erosion score at the joint or facet level } \\
\hline \multirow[t]{2}{*}{$\mathbf{R X}$} & 2 & 18.8 & 86.9 & 79.3 & 28.8 \\
\hline & 3 & 9.8 & 89.1 & 70.6 & 27.1 \\
\hline \multirow[t]{3}{*}{ US } & 1 & 77.9 & 73.9 & 88.8 & 55.7 \\
\hline & 2 & 72.1 & 89.1 & 94.6 & 54.7 \\
\hline & 3 & 67.2 & 100.0 & 100.0 & 53.5 \\
\hline
\end{tabular}

RX: radiography; US: ultrasounds; PPV: positive predictive value; NPV: negative predictive value; * EULAR 2013 Definition of erosive rheumatoid arthritis 
Table 4 Distribution and severity of US erosions in joint assessed in USSe

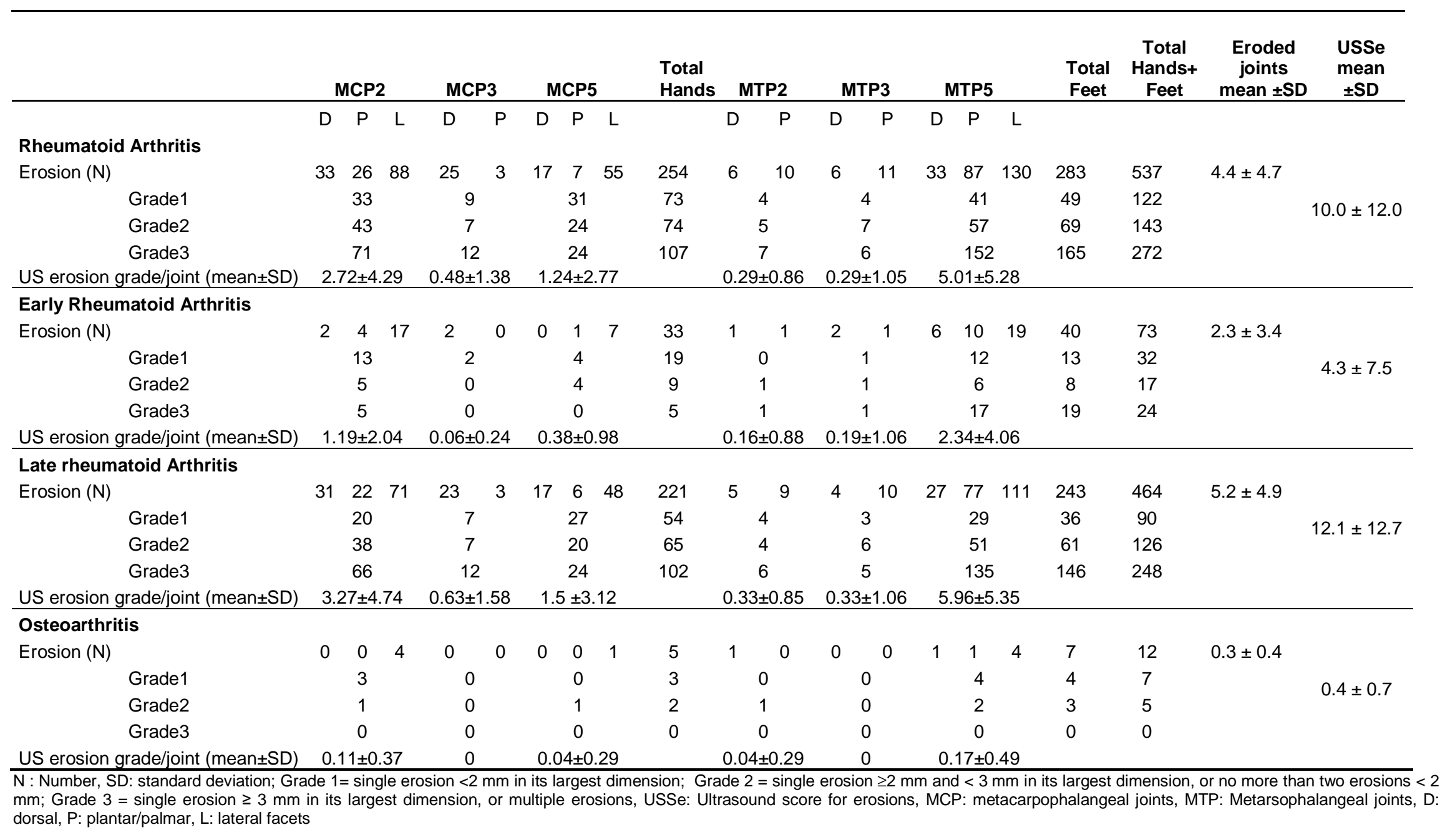

